\title{
Acridinyl methyl esters as photoactive precursors in the release of neurotransmitter amino acids
}

\author{
Ana M. Piloto, ${ }^{a}$ Graham Hungerford, ${ }^{b}$ Susana P. G. Costa, ${ }^{a}$ and M. Sameiro T. Gonçalves*a \\ ${ }^{a}$ Centre of Chemistry, University of Minho, Campus of Gualtar, 4710-057 Braga, Portugal. Fax 351-253604382; Tel: \\ 351-253604372; E-mail: msameiro@quimica.uminho.pt \\ ${ }^{b}$ HORIBA Jobin Yvon IBH Ltd, 45 Finnieston Street, Glasgow G3 8JU, UK. Fax: 44-141 229 6790; Tel: $44-141229$ \\ 6796; E-mail: graham.hungerford@ibh.co.uk
}

$\dagger$ Electronic Supplementary Information (ESI) available: $\left[{ }^{1} \mathrm{H}\right.$ and ${ }^{13} \mathrm{C}$ NMR spectra and normalised decay associated spectra for Acm-OH and conjugates 3a-e]. See DOI: 10.1039/b000000x/

\begin{abstract}
An investigation of the use of an azaheterocycle, acridine, as an alternative photochemically removable protecting group for the carboxylic function of neurotransmitter amino acids was carried out. 9-Bromomethylacridine was used in the reaction with glycine, alanine, glutamic acid, $\beta$-alanine and $\gamma$-aminobutyric acid, to obtain model ester derivatives, which were irradiated at different wavelengths in a photochemical reactor. The process was followed by HPLC/UV, resulting in the release of the active molecule in short irradiation times. The results obtained using $419 \mathrm{~nm}$ irradiation show promise $(35-98 \mathrm{~min})$ for practical purposes. The compounds were further characterised via time-resolved fluorescence to elucidate their photophysical properties and determine the decay kinetics.
\end{abstract}

\section{Introduction}

In recent years, photolabile protecting groups have been the subject of interesting research which has resulted in the emergence of different structures with aromatic and/or heterocyclic skeletons associated with a diversity of applications, not only in the protection of functional groups for synthetic applications, but also as phototriggers for the study of numerous processes in biotechnology and cell biology. ${ }^{1-3}$

Phototriggers allow rapid release of bioactive molecules from their inactive caged precursors upon photolysis. ${ }^{4-6}$ In several cases, the biological activity is blocked through the presence of a covalently linked fluorophore, that upon irradiation cleaves the fluorophore and restores function. The use of fluorescent photolabile protecting groups allows the visualization, quantification, and the follow-up of spatial distribution, localization, and depletion of the active compound through the monitoring of its fluorescent caged precursor using fluorescent techniques, in addition to the time and space 
controlled delivery of the target molecule. ${ }^{7}$ Among these groups are pyrene, ${ }^{8,9}$ phenanthrene, ${ }^{8}$ anthracene, ${ }^{10}$ perylene, ${ }^{11}$ anthraquinone ${ }^{8}$ coumarin, ${ }^{12-14}$ benzocoumarin, ${ }^{15-17}$ thiobenzocoumarin, ${ }^{18}$ quinolone, ${ }^{14}$ and benzoxazole ${ }^{19}$ moieties, which can be used in the protection of different functional groups.

Acridine and its derivatives are planar tricyclic aromatic molecules which fluoresce at the shorter wavelength end of the visible region with high fluorescence quantum yield. ${ }^{20,21}$ Over the time, these compounds have found application as derivatizing agents, being recently reported, for example, as fluorescent chemosensors for metal ions. ${ }^{22-26}$

The photocontrolled release in time and space for the study of the kinetics of bioactive molecules is an established technique for the study of fast biological processes involving neurotransmitters, such as amino acids, nucleotides and physiological amines. As a result, there is a strong interest in the search for more efficient photolabile protecting groups with ability to cleave under irradiation at higher wavelengths, in order to minimise cellular damage.

As a continuation of our research interests, ${ }^{13-19}$ it is now reported the synthesis of fluorescent acridinyl conjugates of glycine $\mathbf{3 a}$, alanine $\mathbf{3 b}$, glutamic acid $\mathbf{3 c}, \beta$-alanine $\mathbf{3 d}$ and $\gamma$-aminobutyric acid (GABA) 3e. The study of their photorelease in different conditions, in a photochemical reactor equipped with lamps of 254, 300, 350 and $419 \mathrm{~nm}$ was carried out. Cleavage kinetic data was obtained by HPLC/UV monitoring.

\section{Results and discussion}

A series of $N$-(tert-butoxycarbonyl)-neurotransmitter amino acids 1 (glycine, alanine, glutamic acid, $\beta$-alanine and $\gamma$-aminobutyric acid) were reacted with 9-bromomethylacridine $2^{25}$ to afford the corresponding heterocyclic ester derivatives 3, via a potassium fluoride coupling in $N, N$ dimethylformamide, at room temperature (Scheme 1 and Table 1). ${ }^{27}$ The acridin-9-yl methylene group will be designated in this report by a three-letter code (Acm) for simplicity of naming the various fluorescent derivatives, as indicated in Table 1. 


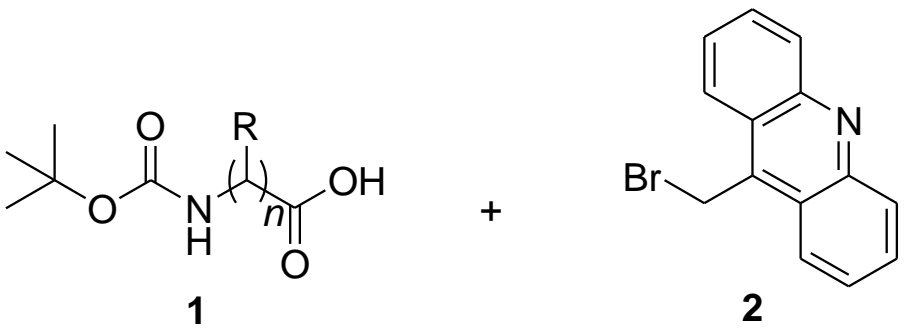
a $n=1, \mathrm{R}=\mathrm{H}$
b $n=1, \mathrm{R}=\mathrm{Me}$
c $n=1, \mathrm{R}=\left(\mathrm{CH}_{2}\right)_{2} \mathrm{CO}_{2} \mathrm{Me}$
d $n=2, \mathrm{R}=\mathrm{H}$
e $n=3, \mathrm{R}=\mathrm{H}$

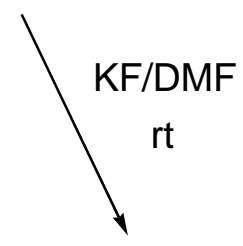

$1+\underset{\text { by-products }}{\text { photo }}$

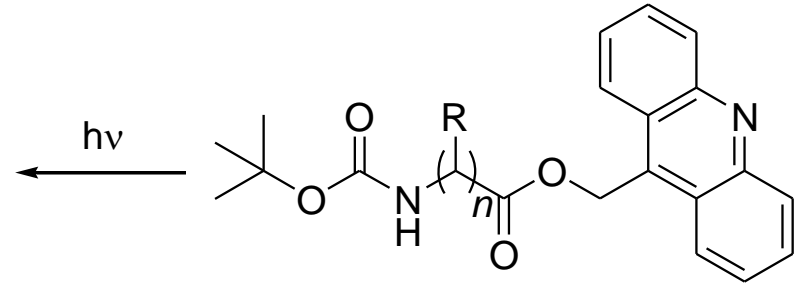

3

Scheme 1. Synthesis of acridinyl methyl ester conjugates 3a-e

All new compounds were fully characterised by high resolution mass spectrometry, IR, ${ }^{1} \mathrm{H}$ and ${ }^{13} \mathrm{C}$ NMR spectroscopy. ${ }^{1} \mathrm{H}$ NMR spectra showed signals of the amino acid residues, such as the $\alpha-\mathrm{CH}$ ( $\delta$ 4.26-4.43 ppm), side chain $\beta-\mathrm{CH}_{2}, \beta-\mathrm{CH}_{3}$ and $\gamma-\mathrm{CH}_{2}(\delta 1.21-2.40 \mathrm{ppm})$, main chain $\alpha-$, $\beta-$, and $\gamma-$ $\mathrm{CH}_{2}(\delta 1.75-3.40 \mathrm{ppm})$. The heterocycle methylene group was also visible for all conjugates $(\delta 6.0-$ $6.40 \mathrm{ppm})$. Also, the ${ }^{13} \mathrm{C}$ NMR spectra showed the corresponding signals for $\alpha-\mathrm{CH}(\delta 44.93$ or $49.26 \mathrm{ppm})$, side chain $\beta-\mathrm{CH}_{2}, \beta-\mathrm{CH}_{3}$ and $\gamma-\mathrm{CH}_{2}(\delta 17.89-21.30 \mathrm{ppm})$, main chain $\alpha-, \beta-$, and $\gamma-\mathrm{CH}_{2}$ ( $\delta 25.28-42.35 \mathrm{ppm})$. The heterocycle methylene group was also visible for all conjugates $(\delta 49.67-$ $58.32 \mathrm{ppm})$. The confirmation of the presence of the new ester bond linking the amino acid to the acridinyl moiety was also supported by ${ }^{13} \mathrm{C}$ NMR spectra signals at $\delta 170.29-173.19 \mathrm{ppm}$ and IR spectroscopy with a band between 1731 and $1738 \mathrm{~cm}^{-1}$. The UV/Vis absorption and emission spectra of degassed $10^{-5} \mathrm{M}$ solutions in absolute ethanol and in a methanol/HEPES buffer (80:20) solution of ester conjugates 3a-e were measured: absorption and emission maxima, molar absorption coefficients and relative fluorescence quantum yields are also reported (Table 1). Relative fluorescence quantum yields were calculated using 9,10-diphenylanthracene as standard $\left(\Phi_{\mathrm{F}}=0.95\right.$ in ethanol). ${ }^{28}$ For the $\Phi_{\mathrm{F}}$ determination, the fluorescence standard was excited at the wavelengths of maximum absorption found for each one of the compounds to be tested and in all fluorimetric measurements the absorbance of the solution did not exceed 0.1. For all compounds the maximum wavelength of absorption, due to the presence of the heterocyclic chromophore, showed no variation in both solvents $\left(\lambda_{\mathrm{abs}}\right.$ at about $\left.360 \mathrm{~nm}\right)$, and was not influenced by the amino acid 
residue. Derivatives 3a-e displayed emission maxima between 411-435 $\mathrm{nm}$ in both solvents, with moderate Stokes' shifts $(\Delta \lambda, 50-75 \mathrm{~nm})$, and exhibited higher fluorescence quantum yields in methanol/HEPES buffer $\left(0.11<\Phi_{\mathrm{F}}<0.15\right)$.

Table 1. Yields, UV/Vis and fluorescence data for conjugates 3a-e in absolute ethanol and methanol/HEPES buffer (80:20) solution

\begin{tabular}{|c|c|c|c|c|c|c|c|c|c|c|c|c|}
\hline \multirow{2}{*}{\multicolumn{2}{|c|}{ Compound }} & \multirow{2}{*}{$\begin{array}{c}\text { Yield } \\
(\%)\end{array}$} & \multicolumn{5}{|c|}{$\mathrm{EtOH}$} & \multicolumn{5}{|c|}{ MeOH/HEPES (80:20) } \\
\hline & & & $\lambda_{\mathrm{abs}}{ }^{[\mathrm{a}]}$ & $\log \varepsilon$ & $\lambda_{\mathrm{em}}{ }^{[\mathrm{a}]}$ & $\Phi_{\mathrm{F}}$ & $\Delta \lambda^{[\mathrm{a}]}$ & $\lambda_{\mathrm{abs}}{ }^{[\mathrm{a}]}$ & $\log \varepsilon$ & $\lambda_{\mathrm{em}}{ }^{[\mathrm{a}]}$ & $\Phi_{\mathrm{F}}$ & $\Delta \lambda^{[\mathrm{a}]}$ \\
\hline $3 \mathbf{a}$ & $\begin{array}{l}\text { Boc-Gly- } \\
\text { OAcm }\end{array}$ & 69 & 360 & 3.90 & 435 & 0.09 & 75 & 362 & 3.48 & 423 & 0.12 & 61 \\
\hline $3 b$ & $\begin{array}{l}\text { Boc-Ala- } \\
\text { OAcm }\end{array}$ & 93 & 361 & 3.93 & 411 & 0.11 & 50 & 360 & 3.69 & 412 & 0.15 & 52 \\
\hline $3 c$ & $\begin{array}{l}\text { Boc-Glu- } \\
\text { OAcm }\end{array}$ & 19 & 361 & 4.04 & 433 & 0.08 & 72 & 362 & 3.57 & 433 & 0.11 & 71 \\
\hline 3d & $\begin{array}{l}\text { Boc- } \beta \text {-Ala- } \\
\text { OAcm }\end{array}$ & 72 & 361 & 3.91 & 412 & 0.11 & 51 & 361 & 3.79 & 417 & 0.14 & 56 \\
\hline $3 \mathbf{e}$ & $\begin{array}{l}\text { Boc-GABA- } \\
\text { OAcm }\end{array}$ & 49 & 361 & 3.97 & 424 & 0.04 & 63 & 360 & 3.94 & 424 & 0.11 & 64 \\
\hline
\end{tabular}

${ }^{[a]}$ in $\mathrm{nm}$.

In order to evaluate the applicability of the acridin-9-yl-methyl unit as a potential photolabile protecting group for neurotransmitter amino acids, methanol/HEPES buffer (80:20) solutions of derivatives 3a-e were irradiated at different wavelengths $(254,300,350$ and $419 \mathrm{~nm})$ in a Rayonet RPR-100 reactor (Scheme 1, Table 2). The photolysis reaction was monitored by reverse phase HPLC with UV detection, peak areas of the starting material $(A$, average of three runs for each compound) revealing a gradual decrease with time. Plots of $A$ versus irradiation time were obtained for each compound, at the considered wavelengths. The determined irradiation time represents the time necessary for the consumption of the starting materials until less than $5 \%$ of the initial area was detected (Table 2). For each compound and based on HPLC data, the plot of $\ln A$ versus irradiation time showed a linear correlation for the disappearance of the starting material, which suggested a first order reaction, obtained by the linear least squares methodology for a straight line. The photochemical quantum yields $\left(\Phi_{\mathrm{P}}\right)$ were calculated based on half-lives $\left(t_{1 / 2}\right)$, molar absorption coefficients $(\varepsilon)$ and the incident photon flux $\left(\mathrm{I}_{0}\right)$, which was determined by potassium ferrioxalate actinometry. ${ }^{29}$ The photocleavage process was not as efficient as desirable (see $\Phi_{\mathrm{P}}$ in Table 2 ), 
possibly by deactivation via fluorescence pathways that compete with the photochemical reaction, as well as the type of reactor used (open chamber reactor).

Table 2. Irradiation times ( $t_{\text {irr }}$, in min), and photochemical quantum yields $\left(\Phi_{\mathrm{P}}, \times 10^{-3}\right)$ for the photolysis of conjugates 3a-e at 300, 350 and $419 \mathrm{~nm}$ in methanol/HEPES buffer (80:20) solution

\begin{tabular}{ccccccc}
\hline \multirow{2}{*}{ Compound } & \multicolumn{2}{c}{$300 \mathrm{~nm}$} & \multicolumn{2}{c}{$350 \mathrm{~nm}$} & \multicolumn{2}{c}{$419 \mathrm{~nm}$} \\
\cline { 2 - 7 } & $t_{\text {irr }}$ & $\Phi_{\mathrm{P}}$ & $t_{\text {irr }}$ & $\Phi_{\mathrm{P}}$ & $t_{\text {irr }}$ & $\Phi_{\mathrm{P}}$ \\
\hline 3a & 25 & 0.23 & 7 & 0.79 & 35 & 0.16 \\
3b & 18 & 0.33 & 10 & 0.61 & 81 & 0.07 \\
$3 \mathbf{3 d}$ & 22 & 0.16 & 8 & 0.46 & 77 & 0.04 \\
$\mathbf{3 e}$ & 22 & 0.27 & 10 & 0.62 & 98 & 0.06 \\
\hline
\end{tabular}

The release of $N$-tert-butyloxycarbonyl neurotransmitters was accomplished in practicable irradiation times in all the tested wavelengths, the fastest release occurring at $350 \mathrm{~nm}(3-10 \mathrm{~min})$, as expected according to the maximum wavelengths of absorption. Concerning the irradiation at 300 $\mathrm{nm}$ it was observed that photolysis occurred between 14 and $25 \mathrm{~min}$; although $254 \mathrm{~nm}$ is not the most suitable wavelength for biological applications, cleavage of the ester bond required 5-14 min. Regarding the amino acid residue, it was found that its influence on the irradiation times was not marked, as these values were quite similar for all wavelengths of irradiation, but the release of GABA was slightly faster than the remaining amino acids (except at $419 \mathrm{~nm}$, with glycine being faster).

\section{Additionally to monitoring the photolysis process by HPLC/UV}

detection, the release of Boc-protected alanine, as the expected product of the photolysis of conjugate 3b, was also followed by ${ }^{1} \mathrm{H}$ NMR in a methanol- $d_{4} / \mathrm{D}_{2} \mathrm{O}(80: 20)$ solution (Figure 1$)$.

Upon irradiation at $350 \mathrm{~nm}$, the signals due to the alanine in the conjugate form disappeared progressively and were replaced by the corresponding set of signals of Boc-Ala-OH, with the $\alpha-\mathrm{CH}$ and $\beta-\mathrm{CH}_{3}$ appearing at $\delta 4.20$ and $1.45 \mathrm{ppm}$, respectively. The decrease of the benzylic-type $\mathrm{CH}_{2}$ at position 9 of the acridine ring was visible at $\delta 6.30 \mathrm{ppm}$, thus confirming the release of the amino acid, and accompanied by the appearance of a new signal at about $4.30 \mathrm{ppm}$ relating to the Acm$\mathrm{OH}$. Moreover, signals due to by-products related to the acridine ring were also detected in the ${ }^{1} \mathrm{H}$ NMR spectra at higher $\delta$ (Figure 1). 


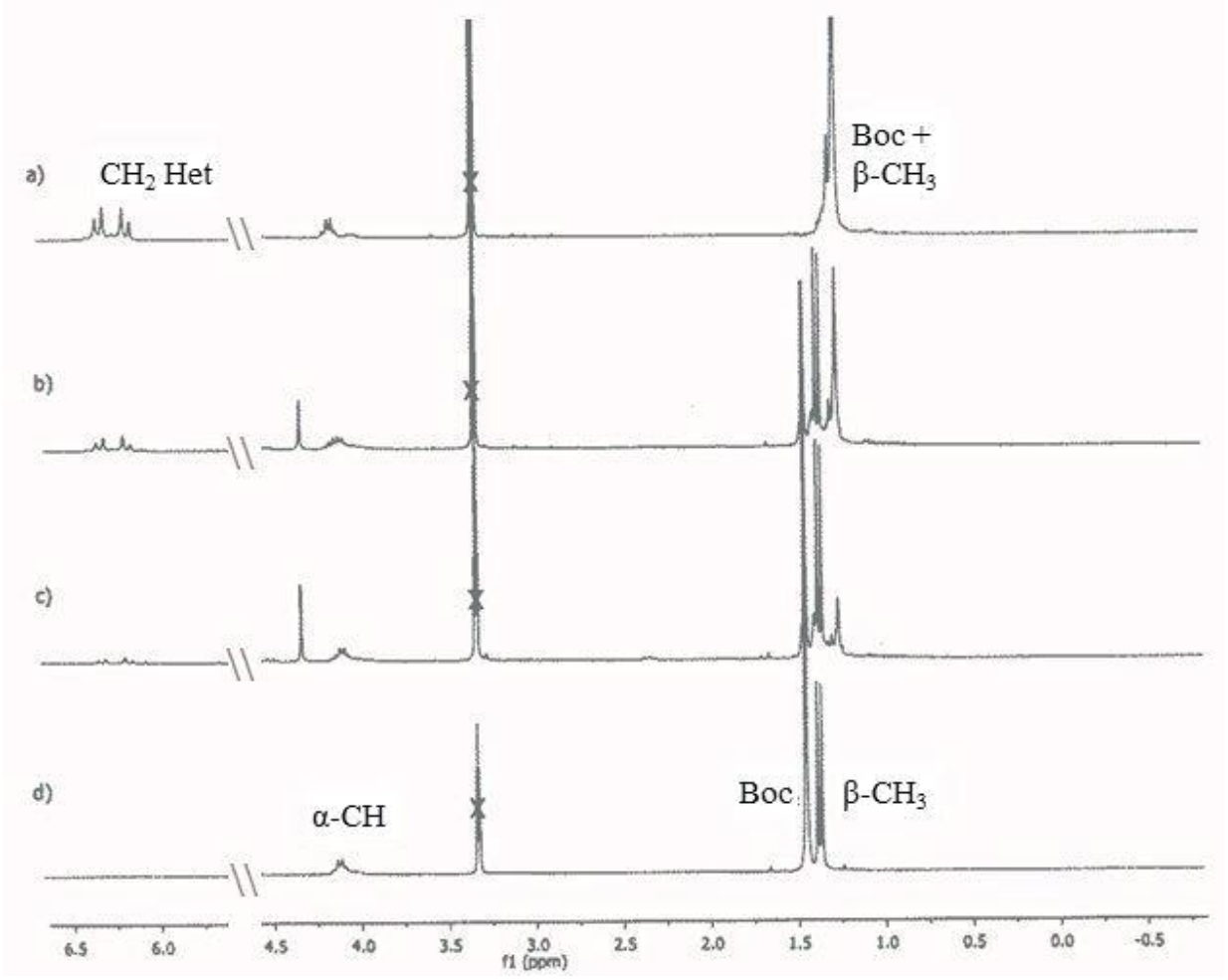

Figure 1. ${ }^{1} \mathrm{H}$ NMR spectra in methanol- $d_{4} / \mathrm{D}_{2} \mathrm{O}(80: 20)$ of the photolysis of conjugate $3 \mathbf{b}(\mathrm{C}=1.1 \times$ $10^{-4} \mathrm{M}$ ) at $350 \mathrm{~nm}$ : (a) before irradiation; (b) after irradiation for $20 \mathrm{~min}$; (c) after irradiation for 40 min; (d) Boc-Ala-OH 1 b.

Table 3. Fluorescence decay parameters for $\mathrm{Acm}-\mathrm{OH}$ in four solvents of different dielectric constant $\left(\alpha_{\mathrm{i}}\right.$ are the normalised pre-exponential factors and the average lifetime $\left(\tau_{\text {ave }}\right)$ is obtained from $\left.\tau_{\text {ave }}=\Sigma \alpha_{\mathrm{i}} \tau_{\mathrm{i}}\right)$.

\begin{tabular}{ccccccccc}
\hline Solvent $(\varepsilon)$ & $\tau_{1} / \mathrm{ps}$ & $\tau_{2} / \mathrm{ns}$ & $\tau_{3} / \mathrm{ns}$ & $\alpha_{1}$ & $\alpha_{2}$ & $\alpha_{3}$ & $\tau_{\text {ave }}$ & $\chi^{2}$ \\
& & & & & & & \multicolumn{1}{l}{${ }^{\mathrm{ns}}$} & \\
\hline Chloroform (5) & $150 \pm 1$ & $1.51 \pm 0.12$ & $5.86 \pm 0.01$ & 0.72 & 0.08 & 0.20 & 1.39 & 1.12 \\
Acetonitrile (38) & $97 \pm 2$ & $2.85 \pm 0.90$ & $5.39 \pm 0.09$ & 0.65 & 0.09 & 0.26 & 1.74 & 1.05 \\
2-Propanol (18) & $401 \pm 8$ & $2.23 \pm 0.45$ & $10.14 \pm 0.03$ & 0.70 & 0.04 & 0.26 & 3.04 & 1.06 \\
Methanol (34) & $483 \pm 9$ & $1.57 \pm 0.08$ & $10.33 \pm 0.01$ & 0.68 & 0.10 & 0.23 & 2.81 & 1.06 \\
\hline
\end{tabular}

Bearing in mind the importance of the development of novel protecting groups cleavable with UV A or even visible radiation, the results indicated that the release of the amino acids at $419 \mathrm{~nm}$ from acridinyl methyl ester derivatives is practicable for organic synthesis and also for caging applications, considering the short irradiation times (35-98 $\mathrm{min}$ ), and the fact that it minimises the side reactions for the remaining functionalities of the molecule. In view of the current use of 9- 
bromomethylacridine as HPLC derivatizing agent for fluorescent labelling of carboxylic acids, ${ }^{25,26}$ the present work represents a novel application, indicative of its versatility and as a result this azaheterocycle can be regarded as an addition to the collection of photolabile protecting groups for the carboxylic acid function.

In order to contribute to the characterisation of these compounds and to elucidate the photophysics associated with the cleavage process observed in the photolysis study, time-resolved fluorescence measurements were performed. An excitation towards the longer wavelength part of the range used in the photolysis study of $375 \mathrm{~nm}$ was chosen. This wavelength may also be useful for future studies involving two-photon excitation, as it is obtainable using femtosecond laser systems. The fluorescence emission of acridine derivatives have, in the main, been reported to decay monexponentially with the lifetime showing a dependency on solvent ${ }^{20,30}$ and substituent groups. $^{31,32}$ In strongly hydrogen bonding solvents, such as water, lifetimes over $10 \mathrm{~ns}$ have been reported..$^{20,2130,33-34}$ The photocleavage is expected to proceed via the formation of an ion pair, which can undergo either a recombination to the initial ester or complete the cleavage with formation of photoproducts (Scheme 1). ${ }^{35}$ These processes should influence the fluorescence decay of the Acm moiety and as the different species can be spectrally different, the ability to obtain time-resolved emission spectra is a powerful technique by which to characterise and elucidate the processes occurring in this type of system.

As well as the conjugates, a model acridin-9-ylmethyl alcohol (Acm-OH) was employed that should be indicative of the photocleaved product. Time-resolved measurements, with the decay monitored at $445 \mathrm{~nm}$ were performed on this compound in different solvents to give an idea of the influence of solvent dielectric constant and hydrogen bonding. The decay kinetics were clearly non exponential, unlike other studies on acridine derivatives. ${ }^{30-32}$ The sum of three exponentials was required to provide a good fit to the data and is indicative of the more complex decay kinetics, even within our model for the photocleaved product. The outcome of the analysis is presented in Table 3 . This shows that the presence of alcohols has a greater effect on the lifetime values than the dielectric constant, as seen by comparing the methanol and acetonitrile data. Also, the influence is on the lifetime rather than the relative proportion of the fluorescing components. The presence of the longer-lived decay, $\sim 10 \mathrm{~ns}$, is in keeping with that reported for acridine in strongly hydrogen bonding solvents. ${ }^{20}$ It should be noted that the average lifetime in methanol is only marginally longer than that reported for acridine. ${ }^{30}$ From these results, it is clear that our substituent group, even in the model, is exerting an influence. As the objective is to harness the photophysics of the acridine moiety to the uncaging of the conjugate system, these data are indicative that this group expresses activity in the excited state, which is not unsurprising as this state has also been reported 
as a stronger proton acceptor with emission from both neutral and cationic forms possible. ${ }^{36}$ Time-resolved fluorescence decays were obtained at $5 \mathrm{~nm}$ wavelength intervals over a range of the fluorescence emission for all of the compounds. The overall fluorescence decay in the methanol/HEPES solution (obtained for each dataset by summing the individual decays obtained at each wavelength) is shown normalised in Figure 2.

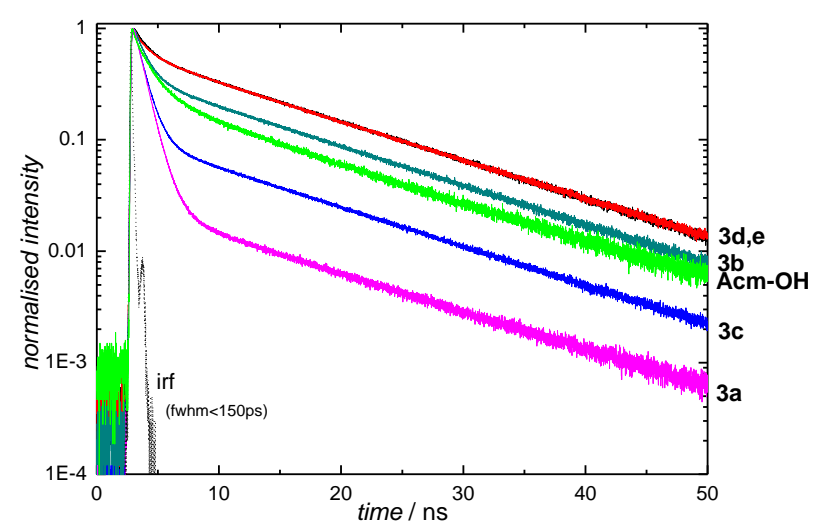

Figure 2. Time-resolved fluorescence decays for Acm-OH and conjugates 3a-e, showing the overall decay (summed over the whole wavelength range) and the instrumental response function (irf)

In all cases the sum of three exponentials was used to fit the data, returning a longer-lived decay of $\sim 12.5 \mathrm{~ns}$, a short-lived subnanosecond fluorescence and a decay component in between the order of a couple of nanoseconds, which is indicative of the presence of different excited state species. Qualitatively it can be seen that the decay curves for 3d and 3e appear similar, with a higher proportion of the longer-lived fluorescence, while 3a exhibits relatively more of the short-lived fluorescence. It is interesting to note that here is an apparent correlation of the proportion of longest-lived fluorescence to the irradiation time at $419 \mathrm{~nm}$ given in Table 2. From these data it appears that processes occurring after excitation are comparable. The main difference is in the relative ratio between these processes. It should also be remembered that the model Acm-OH also exhibits a three exponential decay, thus the influence of the group coupled to the oxygen appears to be a dominant factor.

A preliminary molecular modelling study was performed, in which the difference between the HOMO and LUMO (to give an indication of the orbitals involved) were calculated for PM3 geometry optimised structures, see Figure 3. This modelling indicates that in all compounds, which the exception of $\mathbf{3 d}$ and $\mathbf{3 e}$, the oxygen in the linkage between the acridine and the conjugate is involved. This supports the difference in the decay behaviour of $\mathbf{3 d}$ and $\mathbf{3 e}$ in terms of less of the shorter-lived component in comparison to the other compounds. 


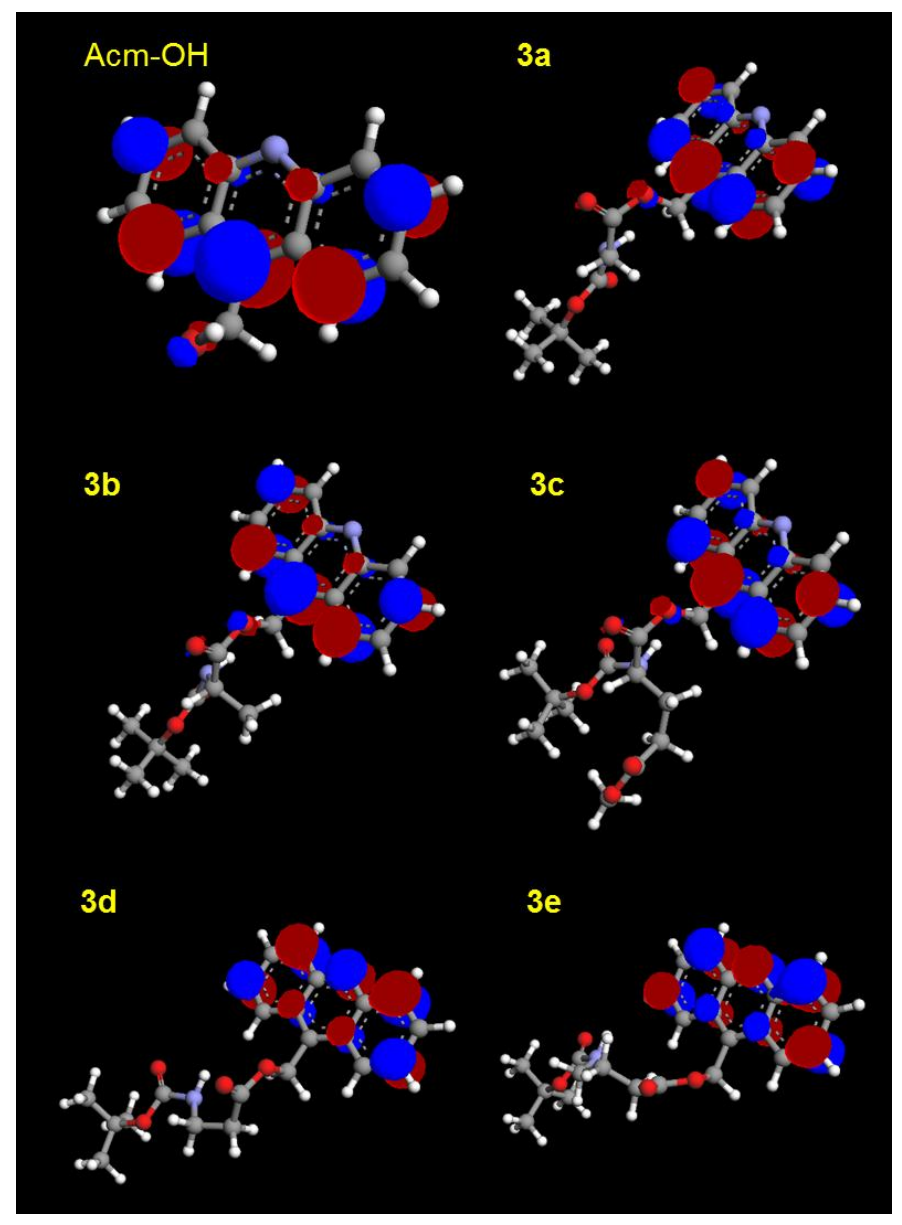

Figure 3. Differences in electron density between the calculated HOMO and LUMO for Acm-OH and conjugates 3a-e (red lobes - negative, blue lobes - positive) 

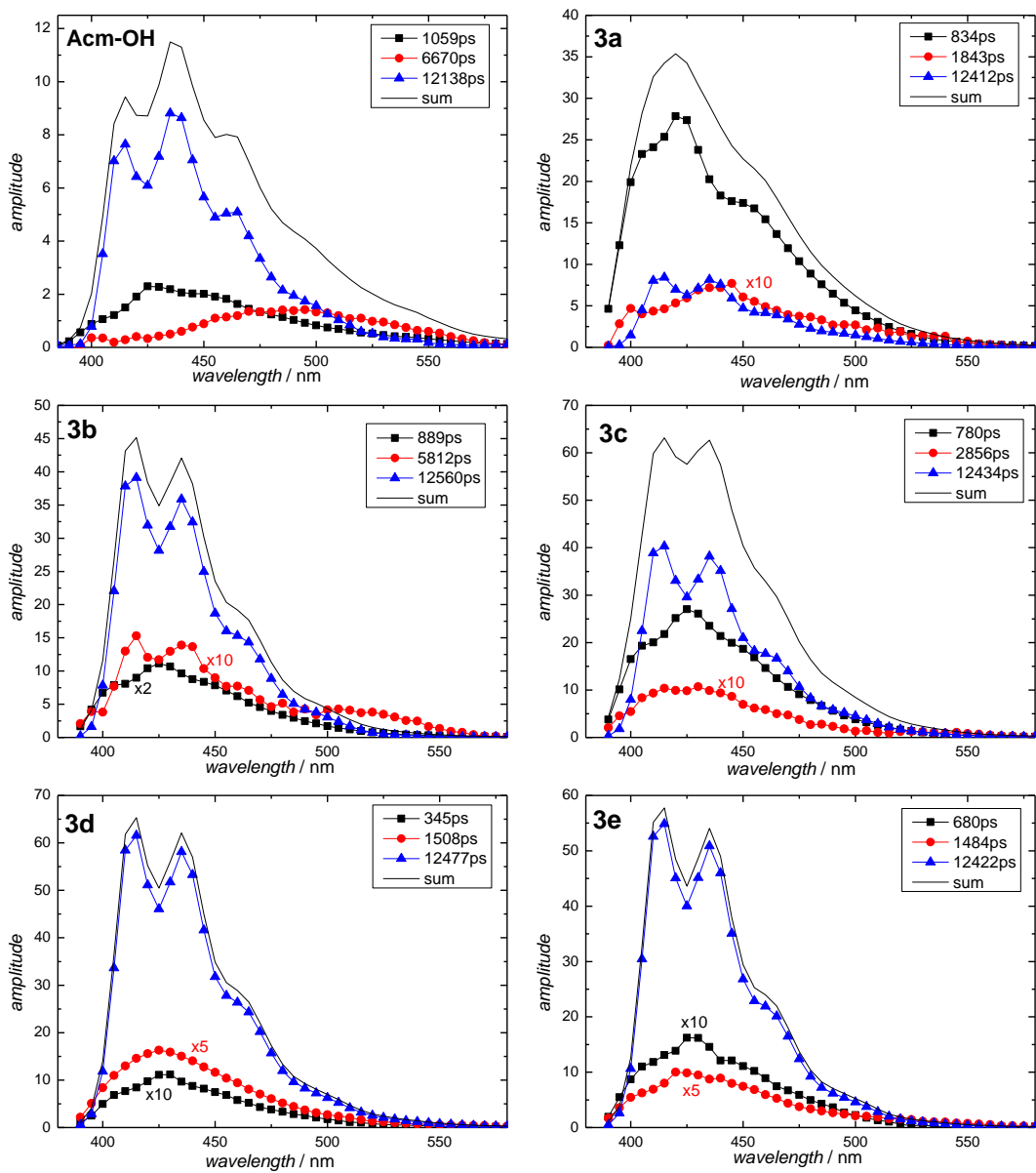

Figure 4. Decay associated spectra for Acm-OH and conjugates 3a-e. The spectra obtained for each decay time (given in ps) are shown along with the sum, which is indicative of the steady state spectrum

From the global analysis of each dataset it was possible to obtain the decay associated spectra (DAS), shown in Figure 4, which can be used to produce spectra linked to the decay times. This can be helpful in identifying the species present, especially related to charge transfer that would be expected as part of the uncaging process. It can be clearly seen that the spectrum associated to the longer-lived fluorescence has structure, as commonly seen in acridine fluorescence, with peak emissions at approximately $415 \mathrm{~nm}$ and $435 \mathrm{~nm}$. The spectrum associated with the shortest-lived fluorescence has a peak emission at $\sim 425 \mathrm{~nm}$ (see supplementary information for normalised spectra). The spectrum associated to the middle decay time is not as well defined, which can relate to the fact that generally its contribution to the overall fluorescence emission is small and may not be so well resolved in the analysis. However, from this figure it seems that common species are present for all of the Acm conjugates. It is also clear from Figure 4, that for the conjugates $\mathbf{3 b} \mathbf{b} \mathbf{3 d}$ and $3 \mathbf{e}$ the major contribution to the overall fluorescence emission is from the longest-lived species, 
in keeping with the model, Acm-OH. Although, its concentration (as indicated by the normalised pre-exponential factor) is inferior to that of the shortest-lived component, which is the dominant process.

The structured spectrum and the lifetime of the longer-lived component correspond well to that of acridine in a strongly hydrogen bonding environment. ${ }^{37}$ This can relate to the methanol/HEPES solvent mixture used. The lack of structure in the spectra of the shortest-lived decay can be indicative of charge transfer. ${ }^{37}$ The spectrum associated with the middle lifetime is, in the main, lacking in structure, pointing to the fact that it is also from an intermediate form. The fact that different species can be elucidated using this technique, shows that complementary concerning the photocleavage process can be obtained to support the photolysis study. The fact that the decay of $\mathrm{Acm}-\mathrm{OH}$ is also complex means that a full characterisation of these conjugates, ie determination of rate constants, is not straightforward. However, the spectrum associated to the intermediate decay time for Acm-OH is notably red-shifted in relation to the other compounds, which may relate to its lack of conjugation. Although the peak emission of this spectrum is similar to that of the shortestlived decay, a longer wavelength shoulder is also present and clearly seen for 3a and $\mathbf{3 b}$ (see supplementary information). A broadening towards longer wavelengths is present for all compounds.

Considering the two shorter-lived components, which maybe more indicative for charge transfer processes involved in the photocleavage process, the values obtained for the model compound $(\mathrm{Acm}-\mathrm{OH})$ are significantly longer than those in the conjugated compounds. It is possible to estimate quenching rates for these lifetimes for the compounds (using $\mathrm{Acm}-\mathrm{OH}$ as a reference) and this is shown in Figure 5. From this, it is clear that the reduction in lifetime is greatest for the GABA and alanine containing compounds (3d,3e), although the amount of these emissions contribute less to the overall fluorescence. The closest resemblance to the model decay times is present in compound $\mathbf{3 b}$, which also expresses some spectral similarities to Acm-OH. It is clear that the conjugate to which the acridine group is attached is influencing its non radiative properties.

Thus, it is apparent from this study that the use of this form of fluorescence measurement can help elucidate the presence of different emitting species, although a complete characterisation is hampered by the complex decay of the model for the photocleaved fluorophore. It can be seen that an emission from the acridine moiety in a hydrogen bonded environment is present and that the use of decay associated spectra can elucidate the presence of intermediate species. Thus, it should be possible, by comparison to the model, in terms of both spectral shape and decay time to gain an insight into the photophysics of this class of molecule with their use as photocleavable labels in mind. 


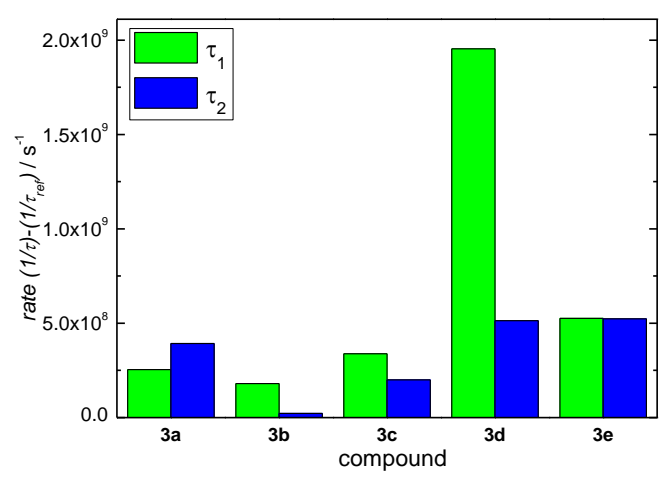

Figure 5. Rates of quenching for the shorter-lived decays for conjugates 3a-e $\left(\tau_{\text {ref }}\right.$ from model compound Acm-OH)

\section{Conclusions}

Novel C-protected neurotransmitter amino acids bearing the acridinyl methyl ester were obtained by a potassium fluoride mediated coupling between 9-bromomethylacridine and $N$-tertbutyloxycarbonylated glycine, alanine, glutamic acid, $\beta$-alanine and $\gamma$-aminobutyric acid. The photorelease of these amino acids from the corresponding fluorescent derivatives in methanol/HEPES buffer (80:20) solutions was achieved by irradiation, with the best results obtained at $350 \mathrm{~nm}$ (3-10 $\mathrm{min})$. However, the results obtained using $419 \mathrm{~nm}$ irradiation show promise (35-98 min) for practical purposes. Time-resolved fluorescence, enabling the calculation of decay associated spectra, showed the presence of the different expected species, in keeping with the results from longer wavelength irradiation.

Given these findings, the acridinyl methyl ester can be considered a suitable option for the photochemical release of functional molecules bearing a carboxylic acid group, for organic synthesis and eventually in caging applications.

\section{Experimental section}

\subsection{General}

All melting points were measured on a Stuart SMP3 melting point apparatus. TLC analyses were carried out on $0.25 \mathrm{~mm}$ thick precoated silica plates (Merck Fertigplatten Kieselgel 60F 254 ) and spots were visualised under UV light. Chromatography on silica gel was carried out on Merck Kieselgel (230-240 mesh). IR spectra were determined on a BOMEM MB 104 spectrophotometer. UV-visible absorption spectra $(200-700 \mathrm{~nm})$ were obtained using a Shimadzu UV/2501PC 
spectrophotometer. NMR spectra were obtained on a Varian Unity Plus Spectrometer at an operating frequency of $300 \mathrm{MHz}$ for ${ }^{1} \mathrm{H}$ and $75.4 \mathrm{MHz}$ for ${ }^{13} \mathrm{C}$ or a Bruker Avance III 400 at an operating frequency of $400 \mathrm{MHz}$ for ${ }^{1} \mathrm{H}$ and $100.6 \mathrm{MHz}$ for ${ }^{13} \mathrm{C}$ using the solvent peak as internal reference at $25^{\circ} \mathrm{C}$. All chemical shifts are given in ppm using $\delta_{\mathrm{H}} \mathrm{Me}_{4} \mathrm{Si}=0 \mathrm{ppm}$ as reference and $J$ values are given in Hz. Assignments were made by comparison of chemical shifts, peak multiplicities and $J$ values and were supported by spin decoupling-double resonance and bidimensional heteronuclear correlation techniques. Mass spectrometry analyses were performed at the "C.A.C.T.I. - Unidad de Espectrometria de Masas", at University of Vigo, Spain. Fluorescence spectra were collected using a FluoroMax-4 spectrofluorometer. All reagents were used as received.

\subsection{General procedure for the synthesis of compounds 3a-e}

9-Bromomethylacridine 2 (1 equiv) was dissolved in dry DMF (2 mL), potassium fluoride (3 equiv) and the corresponding $N$-tert-butyloxycarbonyl amino acid (1.1 equiv) was added. The reaction mixture was stirred at room temperature from 10 to 18 hours. Potassium fluoride was filtered and the solvent was removed by rotary evaporation under reduced pressure, and the crude residue was purified by column chromatography using mixtures of dichloromethane and light petroleum as eluent.

$N$-(tert-butyloxycarbonyl)-glycine (acridin-9-yl) methyl ester, Boc-Gly-OAcm (3a). From reaction of compound $2\left(0.064 \mathrm{~g}, 2.4 \times 10^{-4} \mathrm{~mol}\right)$, in DMF $(2 \mathrm{~mL})$, potassium fluoride $\left(0.041 \mathrm{~g}, 7.08 \times 10^{-3} \mathrm{~mol}\right)$ and $N$-tert-butyloxycarbonylglycine $1 \mathbf{a}\left(0.045 \mathrm{~g}, 2.6 \times 10^{-4} \mathrm{~mol}\right)$, compound $\mathbf{3 a}$ was obtained as a pale brown solid $(0.059 \mathrm{~g}, 69 \%) . \mathrm{mp}=160.1-160.8^{\circ} \mathrm{C}$. TLC (ethyl acetate/ $n$-hexane, 3:7): 0.74. ${ }^{1} \mathrm{H}$ $\mathrm{NMR}\left(\mathrm{CDCl}_{3}, 400 \mathrm{MHz}\right): \delta=1.41\left(\mathrm{~s}, 9 \mathrm{H}, \mathrm{C}\left(\mathrm{CH}_{3}\right)_{3}\right), 3.93\left(\mathrm{~d}, J=5.6 \mathrm{~Hz}, 2 \mathrm{H}, \mathrm{CH}_{2} \mathrm{Gly}\right), 5.02$ (broad s, $1 \mathrm{H}, \mathrm{NH}$ Gly), 6.21 (s, $2 \mathrm{H}, \mathrm{CH}_{2} \mathrm{Acm}$ ), 7.66 (dt, J=7.2 and 0.8 Hz, $2 \mathrm{H}, \mathrm{H}-2$ and H-7), 7.84 (t, $J=7.8$ and $1.2 \mathrm{~Hz}, 2 \mathrm{H}, \mathrm{H}-3$ and H-6), 8.30-8.40 (m, $4 \mathrm{H}, \mathrm{H}-1, \mathrm{H}-4, \mathrm{H}-5$ and H-8) ppm. ${ }^{13} \mathrm{C}$

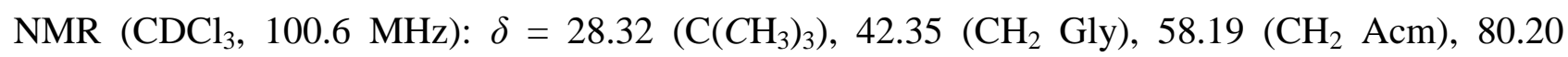
$\left(C\left(\mathrm{CH}_{3}\right)_{3}\right), 124.00$ (C-1 and C-8), 125.32 (C-8a and C-9a), 127.13 (C-2 and C-7), 129.14 (C-4 and C-5), 130.80 (C-3 and C-6), 147.58 (C-4a and C-10a), 155.67 (CONH), $170.29\left(\mathrm{CO}_{2} \mathrm{CH}_{2}\right)$ ppm. IR $\left(\mathrm{KBr} 1 \%, \mathrm{~cm}^{-1}\right)$ : 3332, 2979, 2934, 1758, 1738, 1712, 1660, 1602, 1573, 1520, 1451, 1392, 1367, 1318, 1281, 1250, 1162, 1104, 1056, 967, 862, 845, 751, 703, 666. HRMS (ESI): calcd for $\mathrm{C}_{21} \mathrm{H}_{24} \mathrm{~N}_{2} \mathrm{O}_{4}\left[\mathrm{M}^{+}+\mathrm{H}\right]: 367.16589$; found: 367.16592 .

$N$-(tert-Butyloxycarbonyl)-L-alanine (acridin-9-yl) methyl ester, Boc-Ala-OAcm (3b). From reaction of compound $2\left(0.116 \mathrm{~g}, 4.26 \times 10^{-4} \mathrm{~mol}\right)$, in DMF $(2 \mathrm{~mL})$, potassium fluoride $\left(0.074 \mathrm{~g}, 1.28 \times 10^{-3}\right.$ mol) and $N$-tert-butyloxycarbonyl-L-alanine $\mathbf{1 b}\left(0.089 \mathrm{~g}, 4.69 \times 10^{-4} \mathrm{~mol}\right)$, compound $\mathbf{3 b}$ was 
obtained as a pale yellow solid (0.150 g, 93\%). $\mathrm{mp}=161.1-161.5^{\circ} \mathrm{C}$. TLC (ethyl acetate $/ n$-hexane, 3:7): 0.81. ${ }^{1} \mathrm{H} \mathrm{NMR}\left(\mathrm{CDCl}_{3}, 400 \mathrm{MHz}\right): \delta=1.27$ (d, $J=7.2 \mathrm{~Hz}, 3 \mathrm{H}, \beta-\mathrm{CH}_{3}$ Ala), 1.37 (s, $9 \mathrm{H}$, $\left.\mathrm{C}\left(\mathrm{CH}_{3}\right)_{3}\right), 4.29-4.40$ (m, $1 \mathrm{H}, \alpha-\mathrm{CH}$ Ala), 5.05 (broad s, $\left.1 \mathrm{H}, \mathrm{NH} \mathrm{Ala}\right), 6.0-6.30$ (m, $2 \mathrm{H}, \mathrm{CH}_{2} \mathrm{Acm}$ ), 7.57-7.63 (m, 2 H, H-2 and H-7), 7.75-7.80 (m, 2 H, H-3 and H-6), 8.25 (d, J = 8.8 Hz, 2 H, H-4

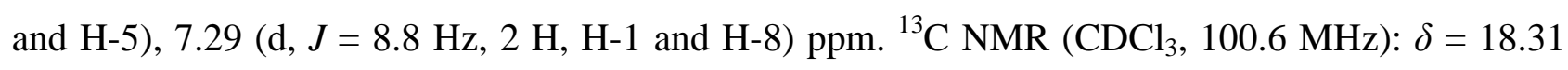
$\left(\beta-\mathrm{CH}_{3} \mathrm{Val}\right), 28.17\left(\mathrm{C}\left(\mathrm{CH}_{3}\right)_{3}\right), 49.26(\alpha-\mathrm{CH} \mathrm{Ala}), 58.32\left(\mathrm{CH}_{2} \mathrm{Acm}\right), 79.85\left(C\left(\mathrm{CH}_{3}\right)_{3}\right), 123.80(\mathrm{C}-8$ and C-9), 125.21 (C-8a and C-9a), 126.73 (C-2 and C-7), 129.88 (C-3 and C-6), 130.28 (C-4 and C5), 136.29 (C-9), 148.68 (C-4a and C-10a), 155.00 (CONH), $173.19\left(\mathrm{CO}_{2} \mathrm{CH}_{2}\right)$ ppm. IR ( $\mathrm{KBr} 1 \%$, $\left.\mathrm{cm}^{-1}\right)$ : 3349, 2980, 2934, 1731, 1681, 1629, 1608, 1557, 1520, 1418, 1392, 1367, 1327, 1252, 1218, 1163, 1110, 1069, 1021, 970, 864, 846, 801, 784, 751, 737, 700. HRMS (ESI): calcd for $\mathrm{C}_{22} \mathrm{H}_{25} \mathrm{~N}_{2} \mathrm{O}_{4}\left[\mathrm{M}^{+}+\mathrm{H}\right]: 381.18088$; found: 381.18086 .

1-(Acridin-9-ylmethyl) 5-methyl 2-((tert-butyloxycarbonyl)amino)pentanedioate, Boc-Glu(OMe)OAcm $(3 \boldsymbol{c})$. From reaction of compound $2\left(0.062 \mathrm{~g}, 2.3 \times 10^{-4} \mathrm{~mol}\right)$, in DMF $(2 \mathrm{~mL})$, potassium fluoride $\left(0.038 \mathrm{~g}, 6.5 \times 10^{-4} \mathrm{~mol}\right)$ and 2-((tert-butoxycarbonyl)amino)-5-methoxy-5-oxopentanoic acid $1 \mathrm{c}\left(0.063 \mathrm{~g}, 2.4 \times 10^{-4} \mathrm{~mol}\right)$, compound $3 \mathrm{c}$ was obtained as a pale yellow orange solid $(0.020 \mathrm{~g}$, $19 \%) . \mathrm{mp}=159.5-160.2{ }^{\circ} \mathrm{C}$. TLC (ethyl acetate/n-hexane, 3:7): 0.53. ${ }^{1} \mathrm{H} \mathrm{NMR}\left(\mathrm{CD}_{3} \mathrm{OD}, 300 \mathrm{MHz}\right)$ : $\delta=1.30\left(\mathrm{~s}, 9 \mathrm{H}, \mathrm{C}\left(\mathrm{CH}_{3}\right)_{3}\right), 1.79-2.11\left(2 \times \mathrm{m}, 2 \mathrm{H}, \beta-\mathrm{CH}_{2} \mathrm{Glu}\right), 2.23-2.40\left(\mathrm{~m}, 2 \mathrm{H}, \gamma-\mathrm{CH}_{2} \mathrm{Glu}\right), 3.57$ (s, $\left.3 \mathrm{H}, \mathrm{OCH}_{3}\right), 4.10-4.24(\mathrm{~m}, 1 \mathrm{H}, \alpha-\mathrm{CH} \mathrm{Glu}), 6.16-6.40$ (m, $\left.2 \mathrm{H}, \mathrm{CH}_{2} \mathrm{Acm}\right), 7.71$ (dt, $J=8.0$ and $0.9 \mathrm{~Hz}, 2 \mathrm{H}, \mathrm{H}-2$ and H-7), 7.89 (dt, $J=8.1$ and $1.2 \mathrm{~Hz}, 2 \mathrm{H}, \mathrm{H}-3$ and $\mathrm{H}-6), 8.20$ (d, $J=8.7 \mathrm{~Hz}, 2 \mathrm{H}$, $\mathrm{H}-4$ and H-5), 8.49 (d, $J=9.0 \mathrm{~Hz}, 2 \mathrm{H}, \mathrm{H}-1$ and $\mathrm{H}-8)$ ppm. ${ }^{13} \mathrm{C} \mathrm{NMR}\left(\mathrm{CD}_{3} \mathrm{OD}, 75.4 \mathrm{MHz}\right): \delta=$ $17.89\left(\beta-\mathrm{CH}_{2} \mathrm{Glu}\right), 19.04\left(\mathrm{C}\left(\mathrm{CH}_{3}\right)_{3}\right), 21.30\left(\gamma-\mathrm{CH}_{2} \mathrm{Glu}\right), 42.60\left(\mathrm{OCH}_{3}\right), 44.93(\alpha-\mathrm{CH} \mathrm{Glu}), 49.67$

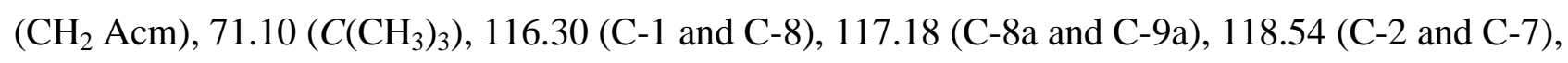
120.24 (C-4 and C-5), 122.46 (C-3 and C-6), 130.60 (C-4a and C-10b), 139.91 (C-9), 163.94 (CONH), $165.14\left(\mathrm{CO}_{2} \mathrm{CH}_{2}\right), 167.01\left(\mathrm{CO}_{2} \mathrm{CH}_{3}\right)$ ppm. IR (KBr 1\%, $\left.\mathrm{cm}^{-1}\right): 3345,2977,2931,2855$, 1738, 1715, 1659, 1603, 1574, 1519, 1451, 1392, 1368, 1320, 1249, 1203, 1164, 1051, 966, 845, 750. HRMS (ESI): calcd for $\mathrm{C}_{25} \mathrm{H}_{29} \mathrm{~N}_{2} \mathrm{O}_{6}\left[\mathrm{M}^{+}+\mathrm{H}\right]$ : 453.20201 ; found: 453.20203 .

$N$-(tert-butyloxycarbonyl)- $\beta$-alanine (acridin-9-yl) methyl ester, Boc- $\beta$-Ala-OAcm (3d). From reaction of compound $2\left(0.062 \mathrm{~g}, 2.3 \times 10^{-4} \mathrm{~mol}\right)$, in DMF $(2 \mathrm{~mL})$, potassium fluoride $(0.040 \mathrm{~g}$, $\left.6.9 \times 10^{-4} \mathrm{~mol}\right)$ and $N$-(tert-butyloxycarbonyl)- $\beta$-alanine $\mathbf{1 d}\left(0.051 \mathrm{~g}, 2.5 \times 10^{-4} \mathrm{~mol}\right)$, compound $\mathbf{3 d}$ was obtained as a pale brown solid $(0.063 \mathrm{~g}, 72 \%) . \mathrm{mp}=162.3-162.6^{\circ} \mathrm{C}$. TLC (ethyl acetate $/ n$ hexane, 3:7): 0.83. ${ }^{1} \mathrm{H} \mathrm{NMR}\left(\mathrm{CDCl}_{3}, 300 \mathrm{MHz}\right): \delta=1.39\left(\mathrm{~s}, 9 \mathrm{H}, \mathrm{C}\left(\mathrm{CH}_{3}\right)_{3}\right), 2.55(\mathrm{t}, J=6.3 \mathrm{~Hz}, 2$ $\mathrm{H}, \alpha-\mathrm{CH}_{2} \beta$-Ala), 3.30-3.40 (m, $2 \mathrm{H}, \beta-\mathrm{CH}_{2} \beta$-Ala), 4.98 (broad s, $\left.1 \mathrm{H}, \mathrm{NH}\right), 6.12$ (s, $2 \mathrm{H}, \mathrm{CH}_{2}$ Acm), 7.62 (dt, $J=7.65$ and $1.2 \mathrm{~Hz}, 2 \mathrm{H}, \mathrm{H}-2$ and $\mathrm{H}-7), 7.79(\mathrm{dt}, J=7.4$ and $1.2 \mathrm{~Hz}, 2 \mathrm{H}, \mathrm{H}-3$ and 
H-6), 8.27 (dt, $J=8.7 \mathrm{~Hz}, 2 \mathrm{H}, \mathrm{H}-4$ and H-5), 8.32 (dt, $J=8.7 \mathrm{~Hz}, 2 \mathrm{H}, \mathrm{H}-1$ and H-8) ppm. ${ }^{13} \mathrm{C}$ NMR $\left(\mathrm{CDCl}_{3}, 75.4 \mathrm{MHz}\right): \delta=28.28\left(\mathrm{C}\left(\mathrm{CH}_{3}\right)_{3}\right), 34.52\left(\alpha-\mathrm{CH}_{2} \beta-\mathrm{Ala}\right), 36.02\left(\beta-\mathrm{CH}_{2} \beta-\mathrm{Ala}\right), 57.72$

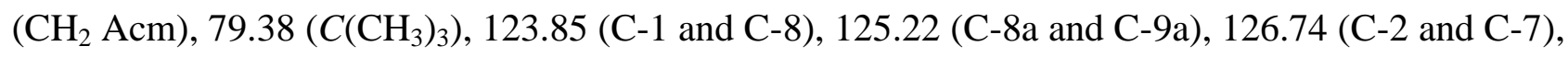
129.93 (C-3 and C-6), 130.26 (C-4 and C-5), 136.66 (C-9), 148.67 (C-4a and C-10a), 155.66 (CONH), $172.14\left(\mathrm{CO}_{2} \mathrm{CH}_{2}\right)$ ppm. IR (KBr 1\%, $\left.\mathrm{cm}^{-1}\right): 3353,3052,2978,2933,1731,1711,1630$, 1603, 1521, 1458, 1443, 1392, 1367, 1250, 1166, 1066, 974, 823, 755, 737, 666. HRMS (ESI): calcd for $\mathrm{C}_{22} \mathrm{H}_{25} \mathrm{~N}_{2} \mathrm{O}_{4}\left[\mathrm{M}^{+}+\mathrm{H}\right]: 381.18088$; found: 381.18086 .

Acridin-9-ylmethyl 4-((tert-butyloxycarbonyl)amino)butanoate, Boc-GABA-OAcm (3e). From reaction of compound $2\left(0.060 \mathrm{~g}, 2.2 \times 10^{-4} \mathrm{~mol}\right)$, in DMF $(2 \mathrm{~mL})$, potassium fluoride $(0.038 \mathrm{~g}$, $\left.6.6 \times 10^{-4} \mathrm{~mol}\right)$ and 4-( tert-butoxycarbonyl)amino)butanoic acid $1 \mathrm{e}\left(0.049 \mathrm{~g}, 2.4 \times 10^{-4} \mathrm{~mol}\right)$, compound 3e was obtained as a white solid $(0.049 \mathrm{~g}, 49 \%) . \mathrm{mp}=160.4-161.1{ }^{\circ} \mathrm{C}$. TLC (ethyl acetate/n-hexane, 3:7): 0.85. ${ }^{1} \mathrm{H} \mathrm{NMR}\left(\mathrm{CDCl}_{3}, 400 \mathrm{MHz}\right): \delta=1.41\left(\mathrm{~s}, 9 \mathrm{H}, \mathrm{C}\left(\mathrm{CH}_{3}\right)_{3}\right), 1.75-1.88(\mathrm{~m}$, $2 \mathrm{H}, \beta-\mathrm{CH}_{2} \mathrm{GABA}$ ), 2.39 (t, $J=7.2 \mathrm{~Hz}, 2 \mathrm{H}, \alpha-\mathrm{CH}_{2} \mathrm{GABA}$ ), 3.10-3.20 (m, $2 \mathrm{H}, \gamma-\mathrm{CH}_{2} \mathrm{GABA}$ ), 4.55 (broad s, $1 \mathrm{H}, \mathrm{NH}$ GABA), 6.15 (s, $2 \mathrm{H}, \mathrm{CH}_{2} \mathrm{Acm}$ ), 7.65 (dt, $J=7.6$ and $1.2 \mathrm{~Hz}, 2 \mathrm{H}, \mathrm{H}-2$ and H-7), 7.83 (dt, $J=8.2$ and $1.2 \mathrm{~Hz}, 2 \mathrm{H}, \mathrm{H}-3$ and H-6), 8.32 (d, $J=8.4 \mathrm{~Hz}, 2 \mathrm{H}, \mathrm{H}-4$ and H-5), 8.36 (d, $J=8.8 \mathrm{~Hz}, 2 \mathrm{H}, \mathrm{H}-1$ and H-8) ppm. ${ }^{13} \mathrm{C} \mathrm{NMR}\left(\mathrm{CDCl}_{3}, 100.6 \mathrm{MHz}\right): \delta=25.28\left(\beta-\mathrm{CH}_{2} \mathrm{GABA}\right)$, $28.35\left(\mathrm{C}\left(\mathrm{CH}_{3}\right)_{3}\right), 31.27\left(\alpha-\mathrm{CH}_{2} \mathrm{GABA}\right), 39.71\left(\gamma-\mathrm{CH}_{2} \mathrm{GABA}\right), 57.59\left(\mathrm{CH}_{2} \mathrm{Acm}\right), 79.29\left(C\left(\mathrm{CH}_{3}\right)_{3}\right)$, 124.06 (C-1 and C-8), 125.35 (C-8a and C-9a), 126.90 (C-2 and C-7), 129.83 (C-4 and C-5), 130.37 (C-3 and C-6), 137.94 (C-9), 148.20 (C-4a and C-10a), 155.89 (CONH), $172.94\left(\mathrm{CO}_{2} \mathrm{CH}_{2}\right)$ ppm. IR $\left(\mathrm{KBr} 1 \%, \mathrm{~cm}^{-1}\right): 3371,2977,1736,1682,1628,1611,1557,1519,1417,1392,1366,1284,1248$, 1163, 1091, 1005, 957, 866, 821, 782, 751, 637. HRMS (ESI): calcd for $\mathrm{C}_{23} \mathrm{H}_{27} \mathrm{~N}_{2} \mathrm{O}_{4}\left[\mathrm{M}^{+}+\mathrm{H}\right]$ : 395.19653; found: 395.19652 .

\subsection{Time-resolved fluorescence measurements}

Time-resolved fluorescence measurements were performed using a HORIBA Scientific FluoroCube-01 equipped with DeltaDiode laser excitation source, ${ }^{38}$ emitting at $375 \mathrm{~nm}$ (running at $10 \mathrm{MHz}$ ), and a TBX-850 detector. Data were acquired by stepping the emission monochromator through $5 \mathrm{~nm}$ increments, over the range 390 to $580 \mathrm{~nm}$, and measuring the decay for a fixed time period. The instrumental response (full width at half maximum $<150 \mathrm{ps}$ ) was also measured. This resulted in the acquisition of 31 time-resolved decays and the instrumental response in each dataset analysis was performed using DAS6 software and the decays reconvoluted with the instrumental response and fitted globally (producing common decay times, $\tau_{\mathrm{i}}$ ) to the sum of exponentials (equation 1) for each dataset. 


$$
I(t)=\sum_{i=1}^{n} \alpha_{i} \exp ^{-t} / \tau_{i}
$$

The goodness of fit was judged in terms of a chi-squared value and weighted residuals. The software also allowed for the summing of all the decay data to produce an overall decay, fitting to which assisted in determining the number of decay times to be included in the analysis. Decay associated spectra (DAS), allowing the spectra to be obtained and related to decay times, were recovered from the global analysis. The pre-exponential values for the individual decays were weighted by the appropriate lifetime value and plotted against wavelength. The sum of the individual DAS for each data was compared to the steady state spectra, and in all cases an agreement was seen.

\subsection{Molecular modelling}

Semi-empirical quantum chemical calculations were performed using ArgusLab 4.0.1 from Mark Thompson, Plenaria Software LLC, Seattle. Structure geometry was optimised using a PM3 model and the highest occupied molecular orbital (HOMO) and lowest unoccupied molecular orbital (LUMO) determined. The difference between them was calculated within the software.

\subsection{Photolysis general}

Photolysis was carried out using a Rayonet RPR-100 chamber reactor equipped with 10 lamps of 254, 300, 350 and $419 \pm 10 \mathrm{~nm}$. HPLC analyses were performed using a Licrospher $100 \mathrm{RP} 18$ (5 $\mu \mathrm{m})$ column in a JASCO HPLC system composed by a PU-2080 pump and a UV-2070 detector with ChromNav software.

\subsection{Photolysis procedure}

A $1 \times 10^{-4} \mathrm{M}$ methanol/HEPES buffer (80:20) solution of compounds 3a-e $(5 \mathrm{~mL})$ were placed in a quartz tube and irradiated in the reactor at the desired wavelength. HEPES buffer solution was prepared in distilled water with HEPES (4-(2-hydroxyethyl)-1-piperazine ethanesulfonic acid) (10 $\mathrm{mM})$, sodium chloride $(120 \mathrm{mM})$, potassium chloride $(3 \mathrm{mM})$, calcium chloride $(1 \mathrm{mM})$ and magnesium chloride $(1 \mathrm{mM})$ and $\mathrm{pH}$ adjusted to 7.2 with aqueous 1 M sodium hydroxide solution. Aliquots of $100 \mu \mathrm{L}$ were taken at regular intervals and analysed by RP-HPLC. The eluent was acetonitrile/water, $3: 1$, at a flow rate of $1.0 \mathrm{~mL} / \mathrm{min}$, previously filtered through a Millipore, type HN $0.45 \mu \mathrm{m}$ filter and degassed by ultra-sound for $30 \mathrm{~min}$. The chromatograms were traced by detecting UV absorption at the wavelength of maximum absorption for each compound (retention time: 3a, 4.3; 3b, 5.0; 3c, 4.5; 3d, 4.9 and $\mathbf{3 e}, 5.1 \mathrm{~min})$. 


\section{Ackowledgements}

Thanks are due to the Fundação para a Ciência e Tecnologia (FCT, Portugal) for financial support to the NMR portuguese network (PTNMR, Bruker Avance III 400-Univ. Minho), FCT and FEDER (European Fund for Regional Development)-COMPETE-QREN-EU for financial support to the research centre CQ/UM [PEst-C/QUI/UI0686/2011 (FCOMP-01-0124-FEDER-022716)] and project PTDC/QUI/69607/2006 (FCOMP-01-0124-FEDER-007449). A PhD grant to A.M.P. (SFRH/BD/61459/2009) is also acknowledged.

\section{References}

1 T. Furuta, in Dynamic Studies in Biology: Phototriggers, Photoswitches and Caged Biomolecules, M. Goeldner, R. S. Givens (Eds.), Wiley-VCH, New York, 2005.

2 G. C. R. Ellis-Davis, Caged compounds: photorelease technology for control of cellular chemistry and physiology, Nat. Methods 2007, 4, 619-628.

3 P. Rai, S. Mallide, X. Zheng, R. Rahmanzadeh, Y. Mir, S. Elrington, A. Khurshid, T. Hasan, Development and Applications of Photo-triggered Theranostic Agents, Adv. Drug Delivery Rev. 2010, 62, 1094-1124.

4 C. G. Bochet, Photolabile protecting groups and linkers, J. Chem. Soc., Perkin Trans. 12002 , 125-142.

5 V. N. R. Pillai, Photoremovable protecting groups in organic synthesis, Synthesis 1980, 1-26.

6 G. Mayer, A. Heckel, Biologically active molecules with a "light switch", Angew. Chem., Int. Ed. 2006, 45, 4900-4921.

7 I. Aujard, C. Benbrahim, M. Gouget, O. Ruel, J.-B. Baudin, P. Neveu, L. Jullien, o-Nitrobenzyl photolabile protecting groups with red-shifted absorption: syntheses and uncaging cross-sections for one- and two-photon excitation, Chem. Eur. J. 2006, 12, 6865-6879.

8 T. Furuta, Y. Hirayama, M. Iwamura, Anthraquinon-2-ylmethoxycarbonyl (Aqmoc): a new photochemically removable protecting group for alcohols, Org. Lett. 2001, 3, 1809-1812.

9 M. Iwamura, C. Hodota, M. Ishibashi, 1-( $\alpha$-Diazobenzyl)pyrene: a reagent for photolabile and fluorescent protection of carboxyl groups of amino acids and peptides, Synlett 1991, 35-36.

10 A. K. Singh, P. K. Khade, Anthracene-9-methanol- a novel fluorescent phototrigger for biomolecular caging, Tetrahedron Lett. 2005, 46, 5563-5566.

11 A. Jana, M. Ikbal, N. D. P. Singh, Perylen-3-ylmethyl: fluorescent photoremovable protecting group (FPRPG) for carboxylic acids and alcohols, Tetrahedron 2012, 68, 1128-1136.

12 B. Schade, V. Hagen, R. Schmidt, R. Herbrich, E. Krause, T. Eckardt, J. Bendig, Deactivation behavior and excited-state properties of (coumarin-4-yl)methyl derivatives. 1. Photocleavage of 
(7-methoxycoumarin-4-yl)methyl-caged acids with fluorescence enhancement, J. Org. Chem. 1999, 64, 9109-9117.

13 A. S. C. Fonseca, M. S. T. Gonçalves, S. P. G. Costa, Photocleavage studies of fluorescent amino acid conjugates bearing different types of linkages, Tetrahedron 2007, 63, 1353-1359.

14 A. S. C. Fonseca, M. S. T. Gonçalves, S. P. G. Costa, Light-induced cleavage of model phenylalanine conjugates based on coumarins and quinolones, Amino Acids 2010, 39, 699-712.

15 M. J. G. Fernandes, M. S. T. Gonçalves, S. P. G. Costa, Comparative study of polyaromatic and polyheteroaromatic fluorescent photocleavable protecting groups, Tetrahedron 2008, 64, 30323038 .

16 M. J. G. Fernandes, M. S. T. Gonçalves, S. P. G. Costa, Neurotransmitter amino acid oxobenzo[f]benzopyran conjugates: synthesis and photorelease studies, Tetrahedron 2008, 64, $11175-11179$.

17 A. M. S. Soares, S. P. G. Costa, M. S. T. Gonçalves, 2-Oxo-2H-benzo[ $h]$ benzopyran as a new light sensitive protecting group for neurotransmitter amino acids, Amino Acids 2010, 39, 121133.

18 A. M. Piloto, A. M. S. Soares, S. P. G. Costa, M. S. T. Gonçalves, Photorelease of amino acids from novel thioxobenzo[f]benzopyran ester conjugates, Amino Acids 2012, 42, 2275-2282.

19 A. M. S. Soares, S. P. G. Costa, M. S. T. Gonçalves, Oxazole ligth triggered protecting groups: synthesis and photolysis of fused heteroaromatic conjugates, Tetrahedron 2010, 66, 8189-8195.

20 L. A. Diverdi, M. R. Topp, Subnanosecond time-resolved fluorescence of acridine in solution, $J$. Phys. Chem. 1984, 88, 3447-3451.

21 Ò. Rubio-Pons, L. Serrano-Andrés, M. Merchán, A theoretical insight into the photophysics of acridine, J. Phys. Chem. A 2001, 105, 9664-9673.

22 M. S. Park, K. M. K. Swamy, Y. J. Lee, H. N. Lee, Y. J. Jang, Y. H. Moon, J. Yoon, A new acridine derivative as a fluorescent chemosensor for zinc ions in a $100 \%$ aqueous solution: a comparison of binding property with anthracene derivative, Tetrahedron Lett. 2006, 47, 81298132.

23 H. N. Lee, H. N. Kim, K. M. K. Swamy, M. S. Park, J. Kim, H. Lee, K.-H. Lee, S. Park, J. Yoon, New acridine derivatives bearing immobilized azacrown or azathiacrown ligand as fluorescent chemosensors for $\mathrm{Hg}^{2+}$ and $\mathrm{Cd}^{2+}$, Tetrahedron Lett. 2008, 49, 1261-1265.

24 Y. Wang, X.Y. Hu, L. Wanga, Z. Shang, J. Chao, W. Jin, A new acridine derivative as a highly selective 'off-on' fluorescence chemosensor for $\mathrm{Cd}^{2+}$ in aqueous media, Sensors Actuat. BChem. 2011, 156, 126-131.

25 W. Tsuzuki, A. Ue, A. Nagao, K. Akasaka, Fluorimetric analysis of lipase hydrolysis of intermediate- and long-chain glycerides, Analyst 2002, 127, 669-673. 
26 K. Todoroki, H. Yoshida, T. Hayama, M. Itoyama, H. Nohta, M. Yamaguchi, Highly sensitive and selective derivatization-LC method for biomolecules based on fluorescence interactions and fluorous separations, J. Chrom. B 2011, 879, 1325-1337.

27 F. S. Tjoeng, G. A. Heavner, Improved preparation of 4-(Boc-aminoacyloxymethyl)phenylacetic acids for use in peptide-synthesis on solid supports utilizing a protecting group removable by photolysis or reduction, Synthesis 1981, 897-899.

28 J. V. Morris, M. A. Mahaney, J. R. Huber, Fluorescence quantum yield determinations. 9,10Diphenylanthracene as a reference standard in different solvents, J. Phys. Chem. 1976, 80, 969974.

29 C. Muller, P. Even, M.-L. Viriot, M.-C. Carré, Protection and labeling of thymidine by a fluorescent photolabile group, Helv. Chim. Acta 2001, 84, 3735-3741.

30 O. Ito, E. Ito, Y. Yoshikawa, A. Watanabe, H. Kokubun, Preferential solvation studies by the fluorescence lifetime of acridine in water-alcohol mixtures, J. Chem. Soc. Faraday Trans. 1996, 92, 227-230.

31 N. Srividya, P. Ramamurthy, V. T. Ramakrishnan, Photophysical studies of acridine(1,8)dione dyes: a new class of laser dyes, Spectrochim. Acta A. 1998, 54, 245-253.

32 V. Karunakaran, P. Ramamurthy, T. Josephrajan, V. T. Ramakrishnan, Solvent effects and photophysical studies of a new class of acridine(1,8)dione dyes, Spectrochim. Acta A. 2002, 58, $1443-1451$.

33 H. P. M. Oliveira, A. J. Camargo, L. G. M. de Macedo, M. H. Gehlen, A. B. F. da Silva, A quantum chemical and photophysical study of acridine-9-N-methacrylamide, J. Mol. Struct. (Theochem), 2004, 674, 213-225.

34 C. D. McGuinness, D. Keszenman-Pereyra, P. Dickenson, C. J. Campbell, B. A. Maltman, T. T. Bachmann, P. Ghazal, J. Crain, Base pair mismatch identification with DNA nanoswitch and long lifetime acridine fluorophore, Sensors Actuators B, 2010, 148, 342-346.

35 R. Schmidt, D. Geissler, V. Hagen, J. Bendig, Mechanism of photocleavage of (coumarin-4yl)methyl esters, J. Phys. Chem. A 2007, 111, 5768-5774.

36 T. Pedzinski, B. Marciniak, G. L. Hug, Quenching of the excited singlet state of acridine and 10methylacridinium cation by thio-organic compounds in aqueous solution, J. Photochem. Photobiol. A: Chem., 2002, 150, 21-30.

37 B. Valeur, Molecular fluorescence: principles and applications, Wiley-VCH, Weinheim, 2001.

38 D. McLoskey, D. Campbell, A. Allison, G. Hungerford, Fast time-correlated single-photon counting fluorescence lifetime acquisition using a $100 \mathrm{MHz}$ semiconductor excitation source, Meas. Sci. Technol. 2011, 22, 067001 (5pp). 